\title{
New Approach to Modelling and Its Application in Transportation in Urban Traffic
}

\author{
Matej Babič \\ Faculty of Information studies, Novo mesto, Slovenia \\ Božo Soldo \\ University North, Department of Civil Engineering, Varaždin, Croatia \\ Janez Povh \\ Faculty of Mechanical Engineering, Ljubljana, Slovenia
}

\begin{abstract}
Urban and suburban transport is a transport system that combines various types of transport, transporting people and goods in the city and the nearest suburban area, as well as performing work on the improvement of the city. The urban transport system is part of a diversified urban economy and includes: vehicles (rolling stock); track devices (rail tracks, tunnels, overpasses, bridges, overpasses, stations, parking lots); marinas and boat stations; power supply devices (traction power substations, cable and contact networks, gas stations); repair shops and factories; depot, garages, service stations; car rental offices; linear communication devices, alarms, locks, traffic control. The city's transport system also includes a bicycle, for which in civilized countries a special bicycle path on the sidewalks is allocated. The urban passenger transport is faced with the task of delivering passengers to their destination with maximum comfort at the minimum cost of time, labour and resources. The territorial development of cities at all times of their history was determined primarily by the speed characteristics of mass intracity movements. Therefore, the famous architect, creator of modern cities Le Corbusier noted that no city can grow faster than its transport. In this article, we introduce a new approach to modelling by using network theory and calculating topological properties of network, which have practical applications in transportation and urban traffic network.
\end{abstract}

Keywords: transportation, modelling and analysis, urban traffic JEL classification: C6, C8, R4

Acknowledgement: The investment is co-financed by the Republic of Slovenia and the European Union under the European Regional Development Fund.

\section{Introduction}

Public passenger transport (PPP) is important for each community, as the current transport system faces well-known problems such as congestion, environmental impact, lack of parking areas, increased safety risks and high energy consumption. On the other hand, PPP is uncompetitive to a passenger car, as it does not allow for comfortable and time-sensitive transport, but forces users to adjust their daily rhythm to the PPP timetable. In rural areas where the population density is lower, and the average age is often higher, due to the greater fragmentation of settlements, the connection with urban centers through PPP is a particularly big problem. The use of cars for transport to the city in Novo mesto (NM) is reflected in the form of traffic jams in the morning and afternoon peaks, and during the day in the form of high 
occupancy of parking spaces around the public areas (hospital, health center); near employers. In the past years, the city municipality has created more than 300 additional parking lots in the vicinity of the center and has eliminated some bottlenecks in traffic, but due to the severely curtailed traffic through the city center, promising after the completion of the renovation of the Main Square in NM, jams.

\section{Open problems}

It is generally known that effective and "smart" PPPs can be organized only by capturing individualized detailed information about the users of this system, supplemented with other data, such as, for example, recordings of cameras on important roads and intersections, data on the use of other systems, weather data and unusual phenomena. Data from smart cards have proven to be an appropriate step in this direction (Agard et al., 2006; Pelletier et al., 2011; Seaborn et al., 2009), but it is necessary to supplement them with location data on traffic participants (Gowtham et al., 2016). In larger cities, this data can be very large, therefore we run against software and hardware requirements, suitable for wholesale (Batty, 2013; Gowtham et al., 2016) which require the use of supercomputing equipment. In our case, during the implementation of the project, we will have smaller amounts of data, and the implementation of simulation calculations (for example, with agent methods) will require greater computational power, so we will run it in parallel using the Rudolf supercomputer.

The new concepts of mobility (travel, co-ownership of vehicles) are on the rise and in many places work perfectly. However, most of these solutions are derived only in large cities, and cities with up to 100,000 inhabitants are generally insufficient to implement business models, i.e. dividing economies (sharing economy (Schor, 2016)) that stand behind these systems. This means that there are no (or we do not know) solutions that would simply be purchased or that private providers themselves would bring to NM for business interest. This is, on the one hand, frustrating, but on the other hand it offers an opportunity for innovative municipalities and regional development agencies. Transport models are a systematic representation of the complex real-world transport and land use system as it exists. They are powerful tools for assessing the impact of transport infrastructure options and for identifying how the transport system is likely to perform in future, which is essential for the development of an effective urban planning practice.

Figure 1

Transport Modelling Process

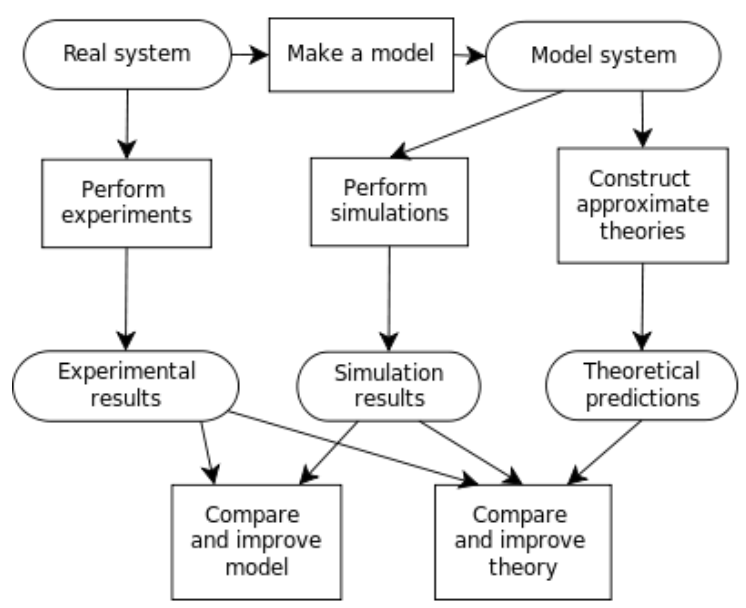

Source: Authors' work 


\section{Motivation}

The main objective of the project is to develop a new model of smart PPP in NM that will be adapted to the specific needs of the citizens of NM:

- the size of the buses and their routes will be adapted to the actual needs;

- the city will be closely linked to the bicycle distribution system and to the public parking system;

o in rural areas, it will be complemented by a call-by-call system.

The project will pursue the following specific objectives:

1. Review, link and analyse available data sources and define a list of additional sources of data that are will be indispensable for the development of smart PPP in NM.

2. To explore how to develop algorithms using artificial intelligence methods, which will well explain and predict the behaviour of PPP users and related systems.

3. To explore how to improve the key parameters of all PPP systems using the simulation methods (number and route of trains, number of buses, number of bikes, new location for bicycle distribution systems and PPP stations, price policy in public car parks, etc.). The improvement criteria will be the flowability, the expected time of travel, the expected occupancy of transport means, and so on.

4. Propose a list of necessary improvements and investments in order to bring a set of mutually unrelated systems serving public transport as an integrated intelligent public passenger transport system in NM.

5. Analyse the introduction of new subsystems of mobility (traveling, car sharing, ...).

6. Prepare a specification for a mobile application and a web site that will give users real-time advice on how to move from PP to point A to point B in NM.

The final result of the project will be the prototype of the solution for the new regulation of PPP and other systems, which will be based on the acquisition of real data on the use of the system and learn from these data, and will provide users in real time to advise on which form PPPs should use for their current or future needs.

\section{Results and discussion}

\section{DS 1: Data acquisition}

The availability of good data on the use of PPP and related systems in Novo mesto (bicycle sharing, public car parks, car for Rudi calling) is a key condition for the development and implementation of smart public transport in Novo mesto. The work will be carried out as part of two tasks:

Task N1.1: Development of a data model.

We will develop a data model and define a set of key variables and engage in the negotiation of RCNM and MONM with subsystem managers so that they actually begin to prepare these data in an appropriate format, and where they are not already, then start collecting them. We have been promised access to data on the use of the bicycle distribution system, the car for the Rudi call transport, and the use of public parking spaces. RCNM also has promised access to anonymous information about the movement of users of the smart card, when available.

Already, NM is striving for a comprehensive acquisition of GPS location data of buses from the LPP and the Rudi car, and for more precise data on the number of passengers on a particular section of each route, but this data is not provided due to the outdated equipment and the lack of interest of the concessionaire for PPP in NM. 
Task N1.2 Defining additional data sources

We will identify the necessary additional data sources (e.g. cameras with traffic lights, weather data, holiday information, holidays, school bus information, etc.) needed to build a smart PPP model in NM.

Task N1.3 Analysis of alternative data sources

We will also analyse alternative data sources for further development of the model, as well as for example, if the Smart Card project will be delayed or not. if there are any other unforeseen obstacles to the use of this information. We will analyse NFC technology, record the number of connections to WIFI points in city buses, or use a special mobile application that also has this feature.

\section{DS2: Data modelling}

Work in this work unit will be organized in the form of two tasks.

Task 2.1: An analysis of the behaviour of users of all systems

Through extensive analyses of collected data, we will search for patterns of behaviour of PPP users and related systems. Especially for all time windows and for typical weather scenarios we will be interested in forecasts:

1. number of passengers on individual routes;

2. times of driving on a particular route;

3. occupancy of individual parking lots;

4. occupancy of wheels from the bicycle distribution system;

We will use state of the art data mining methods to determine the habits of users of all systems that will form an integrated PPP system:

Task 2.2. Development and implementation of smart algorithms

With the methods of artificial intelligence, we will develop algorithms that will give high-quality predictions about the future behaviour of system users at individual time intervals (morning peaks, holidays, various days of the week ...) and in typical physical conditions (bad weather, sun, winter, summer...)

These algorithms will be self-aware - they will use the collected data to update their forecasts. We will implement them as scripts in the R or Orange environment.

Figure 2

New Approach to Modelling by Using Network Theory and Calculating Topological Properties of Network

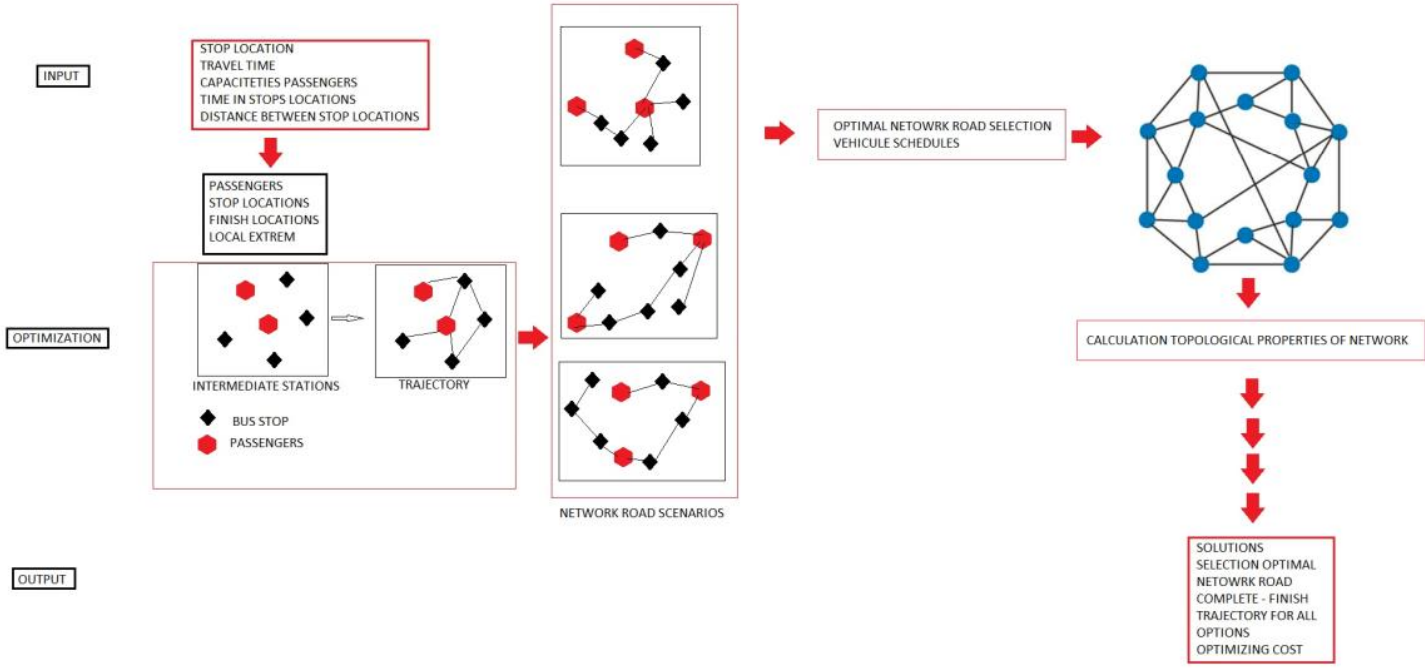

Source: Authors' work 


\section{Conclusion}

Transport is of great importance for the economic and cultural cooperation of Slovenia with other countries, the strengthening and development of the economic management system, in solving social and economic problems. Provision of the territory with a well-developed transport system is one of the factors for attracting population and production, serves as an important advantage for locating productive forces and provides an integration effect. Also, transport creates conditions for the formation of local and national markets. All this creates prerequisites for the further development and improvement of the transport system in general and the passenger transport system in particular. This paper presents some open problem and a new approach to modelling by using network theory and calculating topological properties of network in transportation in urban traffic.

\section{References}

1. Agard, B., Morency, C., Trépanier, M. (2006), "Mining public transport user behaviour from smart card data", IFAC Proceedings Volumes, Vol. 39, No. 3, pp. 399-404.

2. Batty, M. (2013), "Big data, smart cities and city planning", Dialogues in Human Geography, Vol. 3, No. 3, pp. 274-279.

3. Gowtham, J. S., Mehdi, M. J. (2016), "Smart public transport", International Journal of Research in Advanced Engineering Technologies, Vol. 5, No. 5, pp. 17-22.

4. Pelletier, M. P., Trépanier, M., Morency, C. (2011), "Smart card data use in public transit: A literature review", Transportation Research Part C: Emerging Technologies, Vol. 19, No. 4, pp. 557-568.

5. Seaborn, C., Attanucci, J., \& Wilson, N. (2009), "Analyzing multimodal public transport journeys in London with smart card fare payment data", Transportation Research Record: Journal of the Transportation Research Board, Vol. 2121, No. 1, pp. 55-62.

6. Schor, J. (2016), "Debating the Sharing Economy", Journal of Self-Governance \& Management Economics, Vol. 4, No. 3, pp. 7-22. 


\section{About the authors}

Matej Babič received his Ph.D. degree in Computer Science from the Faculty of Electrical Engineering and Computer Science of the University of Maribor, Slovenia. He studied Mathematics at the Faculty of Education in Maribor. His research interest is in fractal geometry, graph theory, intelligent systems and hybrid machine learning. The author can be contacted at babicster@gmail.com.

Bozo Soldo was born in 1971 in Britvica - Bosnia and Herzegovina. He enrolled at the Faculty of Geotechnics of the University of Zagreb in 1989, where he studied VI. graduated in 1993, and VII. The degree completes the degree of graduate work in 1995. He is the winner of the Rector's Award at the University of Zagreb. He graduated in 2000 at the Faculty of Civil Engineering, University of Zagreb. From 1996 to 2003 he was employed in the statute of the research novice and involved in the work of scientific research projects. Participates in teaching at the Faculty of Geotechnics in a multi-level exercise program. Academic degree of Doctor of Technical Sciences, a scientific field of construction, gained in 2004 at the Faculty of Civil Engineering, University of Zagreb. He is also a co-author of about 70 professional and scientific articles. Since 2011, she has been a professor of science in science, a scientific field of Construction. The experience of designing and supervising civil engineering reaches back 15 years. He is one of the founders of the Construction Study at the Veleučilište of Varaždin, and to this day he is the head of the Construction Study. Since 2014, he is a permanent employee of the North University, head of the Department of Architecture, where he teaches several professional geotechnical courses and participates in teaching in the History of Construction. He has been awarded several awards and acknowledgments by the University, the Rotary Club, the Croatian Association of Builders, etc. He actively participates and works on the promotion of architectural science and profession and projects of benefit to the narrower and wider region. The author can be contacted at bozo.soldo@unin.hr.

Janez Povh, researcher at the Faculty of Mechanical Engineering, University of Ljubljana, University of Ljubljana and until 2014 Dean of the Faculty of Information Studies in Novo mesto, graduated in 1998 at the Faculty of Mathematics and Physics (Department of Applied Mathematics). In 2002, he also defended the master's thesis at the same faculty, and in 2008 also received a doctoral dissertation with the title Application of semidefinite and copositive programming and combinatorial optimization. He is currently engaged in the development of new methods in mathematical optimization, based on the intensive use of supercomputers. He is the Project Leader of the High Performance Solution for Binary Quadratic Programs, which he conducts with the University of Klagenfurt and the head of the Slovene-Hungarian project entitled Extension of first and second order algorithms for selected classes of optimization problems in order to solve computational complex industrial problems. $\mathrm{He}$ also leads the research group of the Faculty of Mechanical Engineering on the Project of Biomedical Data Proliferation with non-negative matrix factorization. It also participates in the $\mathrm{H} 2020$ projects PRACE-5IP and EXDCl and in the Danube project InnoHPC. He is the co-author of the online course (MOOC) Managing Big Data with $R$ and Hadoop. The author can be contacted at janez.povh@gmail.com. 